\title{
Leptospirose em cães errantes encontrados em campus universitário: avaliação sorológica e exame direto da urina
}

\section{Leptospirosis in stray dogs found in university campus: serological evaluation and urine direct exam.}

\author{
Aline Benitez ${ }^{1}$; Giovana Giuffrida Rodrigues ${ }^{1}$; Daniela Dib Gonçalves ${ }^{2}$; \\ Julieta Catarina Burke ${ }^{3}$; Lucimara Aparecida Alves ${ }^{4}$; \\ Ernst Eckehardt Müller ${ }^{5}$; Julio Cesar de Freitas ${ }^{5 *}$
}

\section{Resumo}

O objetivo deste estudo foi demonstrar a ocorrência de anticorpos antileptospira em cães errantes encontrados entre julho e setembro de 2007, no campus da Universidade Estadual de Londrina - PR. Para o diagnóstico da leptospirose foi realizada a soroaglutinação microscópica (SAM) em 33 amostras de soro e o exame direto da urina em microscópio de campo escuro (CE) em 10 amostras. Na SAM, foram reagentes sete $(21,21 \%)$ amostras e anticorpos contra os sorovares Canicola, Pyrogenes e Castellonis foram detectados com títulos de 200 a 400. No CE foram visualizadas células com morfologia e movimentos compatíveis com Leptospira spp. em uma amostra. Os resultados deste trabalho indicam a necessidade de controle de cães errantes, pois eles podem representar um problema de saúde pública para a população do campus universitário.

Palavras-chave: Leptospira spp, anticorpos, sorologia, diagnóstico, zoonose, sorovar

\begin{abstract}
The aim of this study was to demonstrate the leptospirosis occurrence in stray dogs found in the campus of Universidade Estadual de Londrina - PR., from July to September 2007. The MAT (Microscopic Agglutination Test) was made as diagnostic serological test in 33 serum samples and the direct dark-field microscopy (DFM) in 10 urine samples. In the MAT, seven samples $(21,21 \%)$ reacted and antibodies against the serovars Canicola, Pyrogenes and Castellonis were detected with titles of 200 to 400. In the DFM, were visualized typical Leptospira spp. morphology and motility structures in one sample. These data indicate the necessity of stray dogs' population control because it may represents a public health problem in the university campus population.
\end{abstract}

Key words: Leptospira spp, antibodies, serology, diagnosis, zoonosis, serovar

\footnotetext{
1 Acadêmica de Medicina Veterinária, UEL, Paraná, Brasil.

2 Programa de Pós - Graduação em Ciência Animal, DMVP, UEL, Paraná, Brasil.

3 Residente em Medicina Veterinária Preventiva, DMVP, UEL, Paraná, Brasil.

4 Bioquímica do Laboratório de Leptospirose, DMVP, UEL, Paraná, Brasil.

5 Departamento de Medicina Veterinária Preventiva, DMVP, UEL, Paraná, Rodovia Celso Garcia Cid (PR 445), km 380; 86051-990; CP 6001. Prof. Dr. Julio Cesar de Freitas; Tel.: (43) 3371-4765; Fax: (43) 3371-4714 E-mail: freitasj@uel.br

* Autor para correspondência.
} 


\section{Introdução}

A leptospirose é uma zoonose de ocorrência mundial, causada por espécies de Leptospira spp.. De acordo com características sorológicas, a espécie L. interrogans está distribuída em 23 sorogrupos que compreendem mais de 250 sorovares com similaridades antigênicas (FAINE, 1999). Os sorovares variam de acordo com a região geográfica em que são encontrados e em função dos aspectos ecológicos que as caracterizam (BOLIN, 1996).

A transmissão da doença aos animais e ao homem ocorre pelo contato direto com a urina ou com órgãos de animais infectados, ou indireto, quando expostos ao ambiente contaminado com a bactéria, como água, solos úmidos, vegetação ou fômites (FAINE, 1982).

Os cães podem eliminar leptospiras vivas através da urina durante períodos variados sem apresentar sinais clínicos (FAINE, 1982), e pelo estreito convívio com o homem, podem ser considerados importantes transmissores desta infecção.

No Brasil, estudos de leptospirose em cães errantes em Pelotas, RS, Campina Grande, PB e Itapema, SC, encontraram respectivamente $34,80 \%, 21,40 \%$ e $10,50 \%$ de prevalência (ÁVILA et al., 1998; BATISTA et al., 2004; BLAZIUS et al., 2005).

Estes cães, sem donos ou de proprietários relapsos, ao ingerirem água empoçada, revirarem lixos com restos alimentares contaminados com a urina de roedores/animais infectados possuem 3,59 vezes maior risco de se infectarem com esta doença (MAGALHÃES, 2007).

O objetivo deste estudo foi demonstrar a ocorrência de anticorpos anti Leptospira spp. nos cães errantes encontrados no período de julho a setembro de 2007 no campus da Universidade Estadual de Londrina (UEL) - PR.

\section{Material e métodos}

No período de julho a setembro de 2007, foram identificados e localizados 33 cães errantes, $19(57,60 \%)$ machos e $14(42,40 \%)$ fêmeas, sem raça definida (SRD), com idades variadas e status imunológico desconhecido no campus da Universidade Estadual de Londrina, PR(UEL). Estes animais eram mantidos por membros da comunidade universitária, que ofereciam água, alimento e abrigo de forma improvisada e inadequada, facilitando a permanência desses cães no campus.

Foram coletadas amostras de sangue, assepticamente por venopunção cefálica ou jugular, de 33 cães, e o soro obtido foi estocado a $-20^{\circ} \mathrm{C}$ até a realização do exame no Laboratório de Leptospirose do Departamento de Medicina Veterinária Preventiva (DMVP) da UEL.

Para o diagnóstico sorológico da leptospirose, foi realizada a prova de soroaglutinação microscópica (SAM) com 22 sorovares de referência: Australis, Bratislava, Autumnalis, Butembo, Castellonis, Bataviae, Canicola, Whitcombi, Cynopteri, Djasiman, Grippotyphosa, Hebdomadis, Copenhageni, Icterohaemorrhagiae, Javanica, Panama, Pomona, Pyrogenis, Hardjo, Wolffi, Shermani e Tarassovi.

Os soros que apresentaram $50 \%$ ou mais de aglutinação na diluição 1:100 foram considerados reagentes e então diluídos seriadamente para a determinação da diluição máxima positiva(MYERS, 1985). Foi considerado o sorovar mais provável aquele que apresentou o maior título aglutinante (VASCONCELLOS et al., 1997).

O exame direto da urina em microscópio de campo escuro (CE) foi realizado no máximo dez minutos após a colheita, por cistocentese ou micção natural, em amostras de dez animais. Foi considerada positiva aquela que apresentou células com morfologia e movimentação compatíveis com Leptospira spp. (FAINE, 1999). Os outros 23 cães do estudo não apresentavam na abordagem volume de urina suficiente para a coleta. 


\section{Resultados}

Das 33 amostras de soro testadas na SAM, 07 (07/33) foram reagentes para um ou mais sorovares com títulos de 200 a 400. Foi possível determinar o sorovar mais provável em cinco amostras: Canicola em três (03/07), Pyrogenes em uma (01/07) e Castellonis em uma (01/07). Em duas amostras, foram detectados títulos iguais de anticorpos contra dois sorovares o que não permitiu identificar o mais provável (Tabela 1).

Tabela 1. Sorovares mais prováveis e títulos de anticorpos anti-Leptospira spp. detectados na SAM em sete dos 33 cães errantes presentes no campus da Universidade Estadual de Londrina-PR, de julho a setembro de 2007.

\begin{tabular}{lccccc}
\hline & \multicolumn{3}{c}{ Títulos Sorológicos } & \multicolumn{2}{c}{ Total } \\
& 100 & 200 & 400 & $\mathrm{n}$ & $(\%)$ \\
\hline Canicola & - & 03 & - & 03 & $42,88 \%$ \\
Pyrogenes & - & - & 01 & 01 & $14,28 \%$ \\
Castellonis & - & 01 & - & 01 & $14,28 \%$ \\
Canicola + Icterohaemorrhagiae & - & 01 & - & 01 & $14,28 \%$ \\
Canicola + Pyrogenes & - & 01 & - & 01 & $14,28 \%$ \\
\hline Total & - & 06 & 01 & 07 & $100 \%$ \\
\hline
\end{tabular}

Uma amostra de urina apresentou células com morfologia e movimentação compatíveis com Leptospira spp. e foi considerada positiva. Esta amostra foi proveniente de um cão sororreagente ao sorovar Canicola com título de 200.

O mapeamento dos locais onde os cães se encontravam dentro do campus da UEL pode ser visualizado na Figura 1.

\section{Discussão}

A soropositividade $(21,21 \%)$ para leptospirose em cães errantes do campus da UEL-PR é semelhante aos resultados encontrados por Yasuda; Caldas; Oliveira, (1980) e Batista et al. (2004) que descreveram respectivamente $21,60 \%$ e $20,00 \%$ de cães errantes soropositivos para leptospirose na cidade de São Paulo e Patos (PB). Entretanto, Blazius et al. (2005) na cidade de Itapema -SC e Flores et al. (1999) na cidade do México, relataram respectivamente $10,51 \%$ e $38,50 \%$ de cães errantes soropositivos para leptospirose. Segundo Faine
(1999), a ocorrência da leptospirose é influenciada por fatores como deficiências nas condições sanitárias e de infra-estrutura, presença de roedores, aspectos ecológicos característicos de cada região e população analisada.

No Brasil, Ávila et al. (1998) e no México, Flores et al. (1999), relataram sorovares semelhantes aos detectados neste estudo em cães errantes soropositivos para Leptospira spp. O sorovar Canicola, tradicionalmente associado a leptospirose em cães não vacinados nos EUA (BOLIN, 1996) e em cães errantes no Brasil (MORALES; GIRIO; MATHIAS, 1990; FURTADO et al., 1997) também foi evidenciado sorologicamente neste trabalho. Os sorovares Pyrogenes e Castellonis, também foram descritos por Querino et al. (2003) em cães do município de Londrina (PR). Este resultado reforça a importância do controle de cães errantes nesta região como prevenção para a leptospirose humana, pois, de acordo com Stanchi \& Arias (1997), o sorovar Pyrogenes é considerado um dos mais patogênicos ao homem. 


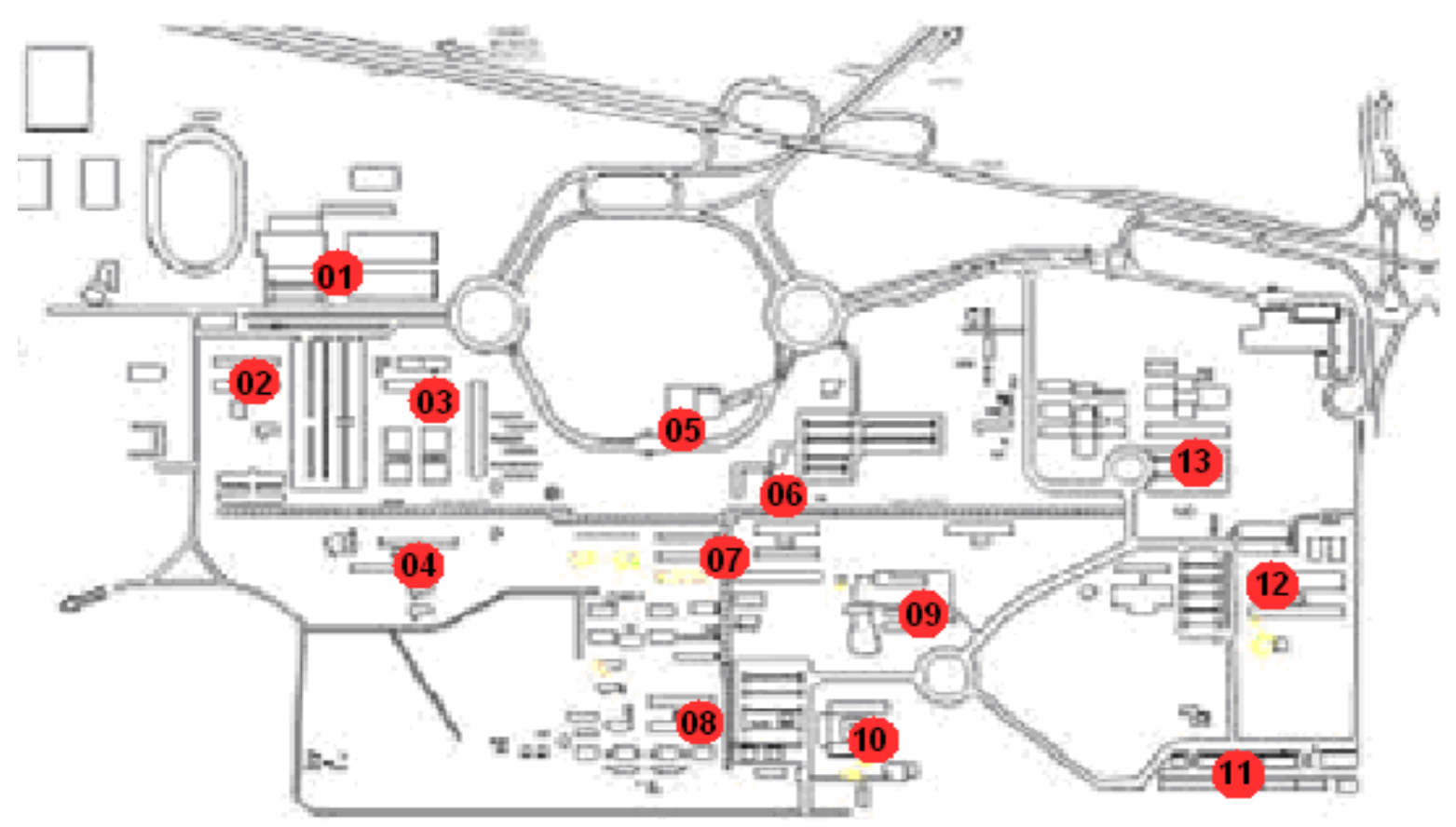

Figura 1. Mapa do campus da Universidade Estadual de Londrina-PR, destacando os pontos onde foram encontrados os 33 cães errantes de julho a setembro de 2007.

Fonte: http://www.uel.br/proplan/mapa-uel/

Legenda (Figura 1):

01: Centro de Educação Física e Desportos (CEF)

02: Centro de Educação, Comunicação e Artes (CECA)

03: Centro de Letras e Ciências Humanas (CCH)

04: Centro de Estudos Sociais Aplicados (CESA)

05: Restaurante Universitário (RU)

06: Núcleo de Bem Estar da Comunidade Universitária (NUBEC)

07: Centro de Ciências Exatas (CCE)

08: Centro de Tecnologia e Urbanismo (CTU) e Centro de Ciências Agrárias (CCA)

09: Prefeitura do Campus Universitário (PCU)

10: Hospital Veterinário (HV)

11: Oficinas

12: Reitoria

13: Cantina

A amostra de urina considerada positiva no CE foi obtida de um cão recém recolhido do campus por um estudante. Este cão não apresentava sinais clínicos sugestivos de infecção por Leptospira spp. e, portanto agia como disseminador desta zoonose tanto no campus universitário da UEL-PR como em seu novo ambiente residencial. Na SAM, o soro deste animal foi reagente ao sorovar Canicola com título de 200.
No campus da UEL - PR são encontrados cães errantes nos vários centros de estudo, além da fazenda escola, restaurante universitário, hospital veterinário e da mata nativa agregada. Nestes locais eles encontram várias possibilidades de infecção por Leptospira spp., tanto pelo contato direto com a urina contaminada dos animais de produção, silvestres e roedores sinantrópicos, quanto pelo indireto, através do ambiente contaminado. Além 
disso, os cães infectados podem representar fonte de infecção para os membros da comunidade universitária, principalmente para aqueles que mantém estes animais oferecendo alimento, água e abrigos improvisados. Segundo Vasconcellos (1993) o cão infectado e assintomático, por eliminar leptospiras viáveis pela urina de forma intermitente durante longos períodos e pela ampla facilidade de deslocamento, pode ser considerado responsável pela persistência dos focos de leptospirose e fonte de manutenção do agente no ambiente.

Além da leptospirose, o cão pode contribuir para a manutenção, distribuição e transmissão de outras doenças especialmente zoonoses como as borrelioses, leishmanioses, raiva e dermatofitoses (SOARES et al., 2000; CARMO, 2002; MIRANDA; SILVA; MOREIRA, 2003; GURTLER; DINIZ; NICCHIO, 2005).

Os resultados encontrados neste estudo sugerem a presença de cães errantes infectados com Leptospira spp. no campus da UEL-PR e a participação destes animais como potenciais mantenedores desta zoonose.

Comitê de Ética: Aprovado pelo Comitê de Ética em Experimentação Animal (CEEA) da Universidade Estadual de Londrina (UEL) - Parecer $n^{\circ} .32 / 07$.

\section{Referências}

ÁVILA, M. O.; FURTADO, L. R. I.; TEIXEIRA, M. M.; ROSADO, R. L. I.; MARTINS, L. F. S.; BROD; C. S. Aglutininas anti-leptospíricas em cães na área de influência do Centro de Controle de Zoonoses, Pelotas, RS, Brasil, 1995. Ciência Rural, Santa Maria, v. 28, n. 1, p. 107-110, 1998.

BATISTA, C. S. A.; AZEVEDO, S. S.; ALVES; C. J.; VASCONCELLOS, S. A.; MORAIS, Z. M.; CLEMENTINO, I. J.; LIMA, F; S.; ARAUJO NETO, J. O. Soroprevalência de leptospirose em cães errantes da cidade de Patos, Estado da Paraíba, Brasil. Brazilian Journal of Veterinary Research and Animal Science, São Paulo, v. 41, n. 2, p. 131-136, 2004.
BLAZIUS, R. D.; ROMÃO, P. R. T.; BLAZIUS, E. M. C. G.; SILVA, O. S. Ocorrência de cães errantes soropositivos para Leptospira spp. na cidade de Itapema, Santa Catarina, Brasil. Cadernos de Saúde Pública, v. 21, n. 6, p. 1952-1956, 2005.

BOLIN, C. A. Diagnosis of leptospirosis: a reemerging disease of companion animals. Seminars in Veterinary Medicine and Surgery (small animal), v. 11, n. 3, p. 166171, 1996.

CARMO, E. H. Leishmaniose Visceral no Brasil: situação atual, principais aspectos epidemiológicos, clínicos e medidas de controle.. In:VI REUNIÃO ANUAL DE PESQUISA APLICADA EM LEISMANIOSE. Boletim Eletrônico Epidemiológico FUNASA .Uberaba, ano 02, n. 06, 13/12/2002. Disponível em: <http://bvsms.saude. gov.br/bvs/periodicos/boletim_eletronico_epi_ano02_ n06.pdf $>$. Acesso em:13/06/2009

FAINE, S. Guidelines for the control of leptospires. 2 ed. Geneva, World Health Organization, 1982, 171p. (Who offset publications, n. 67).

FAINE, S.; ADLER, B.; BOLIN, C.; PEROLAT, P. Leptospira and leptospirosis. 2 ed. Austrália: Melbourne, Medisci, 1999. 272p.

FLORES, A. R.; MOCTEZUMA, A. P.; RIOL, M. A. R.; BADILLO, M. L. O. Soroprevalência de leptospirosis en perros callejeros del norte de la ciudad de México. Veterinaria México, v. 30, n. 1, p. 105-107, 1999.

FURTADO, L. R. I.; AVILA, M. O.; FEHLBERG, M. F. B.; TEIXEIRA, M. M.; ROSADO, R. L. I.; MARTINS, L. F. S.; BROD, C. S. Prevalência e avaliação de fatores de risco à leptospirose canina, no Município de Pelotas, RS. Arquivos do Instituto Biológico, v. 64, n. 1, p. 57-61, 1997.

GURTLER, T. G. R.; DINIZ, L. M.; NICCHIO, L. Tinea capitis micro-epidemic by Microsporum canis in a day care center of Vitória - Espírito Santo (Brazil). Anais Brasileiro de Dermatologia. Rio de Janeiro, v. 80, n. 3, p. 267-272, 2005.

MAGALHÃES, D. F.; SILVA, J. A.; MOREIRA, E. C.; WILKE, V. M. L.; NUNES, A. B. V.; HADDAD, J. P. A.; MENESES, J. N. C. Perfil dos cães sororreagentes para aglutininas anti-Leptospira interrogans em Belo Horizonte, Minas Gerais, 2001/2002. Arquivo Brasileiro de Medicina Veterinária e Zootecnia, v. 59, n. 5, p. 13261329, 2007.

MIRANDA, C. F. J.; SILVA, J. A.; MOREIRA, E. C. Raiva humana transmitida por cães: áreas de risco em Minas Gerais, Brasil, 1991-1999. Caderno de Saúde Pública, Rio de Janeiro, v. 19, n. 1, p. 91-99, 2003. 
MORALES, A.; GÍRIO, R. J. S.; MATHIAS, A. Casos de leptospirose em cães atendidos no Hospital Veterinário da FCAVJUNESP, durante o período de 1986 a 1990. Ciência Veterinária, v. 4, n. 2, p. 5-6, 1990.

MYERS, D. M. Leptospirosis: Manual de métodos para el diagnóstico de laboratório. Buenos Aires: Centro Panamericano de Zoonosis, OPS/OMS, 1985.

QUERINO, A. M. V.; DELBEM, A. C. B.; OLIVEIRA, R. C.; SILVA, F. G.; MULLER, E. E.; FREIRE, R. L.; FREITAS, J. C. Fatores de risco associados à leptospirose em cães do município de Londrina-PR. Semina, Londrina, v.24, n.1, p.27-34, jan./jun. 2003.

SOARES, C. O.; ISHIKAWA, M. M., FONSECA, A. H.; YOSHINARI, N. H. Borrelioses, agentes e vetores. Pesquisa Veterinária Brasileira, Rio de Janeiro, v. 20, n. 1, p. 01-19, jan./mar. 2000.

STANCHI, N. O.; ARIAS, D. O. Consideraciones de la leptospirosis. Avances en Medicina Veterinaria, v. 1, n. 1, p. 20-21, 1997.
VASCONCELLOS, S. A. Leptospirose animal. In: INSTITUTO OSWALDO CRUZ/FUNDAÇÃO NACIONAL DE SAÚDE, 1993, Rio de Janeiro. Anais... Rio de Janeiro: Ministério da Saúde, 1993. p. 62- 65.

VASCONCELLOS, A. S.; BARBARINI, J. R.; UMEHARA, O.; MORAIS, Z. M.; CORTEZ, A.; PINHEIRO, S.R.; FAVERO, A.C.M.; FERREIRA NETO, J. S. Leptospirose bovina. Níveis de ocorrência e sorotipos predominantes em rebanhos dos Estados de Minas Gerais, São Paulo, Rio de Janeiro, Paraná, Rio Grande do Sul e Mato Grosso do Sul. Período de janeiro a abril de 1996. Arquivos do Instituto Biológico. v. 64, n. 2, p. 7-15, 1997.

YASUDA, P. H.; SANTA ROSA, C. A.; YNAGUITA, R. M. Variação Sazonal na Prevalência de Leptospirose em Cães de Rua da Cidade de São Paulo, Brasil. Revista de Saúde Pública, v. 14, n. 4, p. 588- 596, 1980. 